\title{
The Effect of Oxygen Mixing Percentage on Structural, Optical and Electrical Properties of ZnTiO3 Thin-films Grown by Rf Magnetron Sputtering.
}

srinivasa varaprsad H ( $\nabla$ hsvprasad.rs@andhrauniversity.edu.in )

Andhra University College of Engineering https://orcid.org/0000-0002-5764-4224

sridevi P. V

Andhra University College of Engineering

Satya Anuradha M

Andhra University College of Engineering

Srinivas Pattipaka

Vardhaman College of Engineering

pamu D

IIT Guwahati: Indian Institute of Technology Guwahati

\section{Research Article}

Keywords: Thin-film, Optical properties, Swanepoel envelope technique

Posted Date: March 2nd, 2021

DOl: https://doi.org/10.21203/rs.3.rs-254833/v1

License: (c) (1) This work is licensed under a Creative Commons Attribution 4.0 International License.

Read Full License 


\title{
The effect of Oxygen Mixing Percentage on structural, optical and
}

\section{electrical properties of $\mathrm{ZnTiO}_{3}$ thin-films grown by $\mathrm{RF}$ magnetron}

\author{
sputtering. \\ H. Srinivasa Varaprasad ${ }^{1}$, P. V. Sridevi, ${ }^{1}$ M. Satya Anuradha,${ }^{1}$ Srinivas Pattipaka, ${ }^{2}$ \\ D. Pamu, ${ }^{2}$ \\ ${ }^{1}$ Department of Electronics and Communications Engineering, AUCE (A), Andhra University, Visakhapatnam, \\ Andhra Pradesh 530003, India. \\ ${ }^{2}$ Department of Physics, Indian Institute of Technology Guwahati, Guwahati 781039, India. \\ *Corresponding author’s E-mail: prof.pvsridevi@andhrauniversity.edu.in. , \\ hsvprasad.rs@andhrauniversity.edu.in
}

\begin{abstract}
:
Perovskites are important composites in the area of multidisciplinary applications. It is achieved by carefully choosing and tuning the properties of the thin-film at the deposition. In this paper, $\mathrm{ZnTiO}_{3}(\mathrm{ZTO})$ thinfilms were being deposited on quartz and N-Si substrates by RF magnetron sputtering. The thin-films were developed at room temperature, oxygen percentage levels varying from 0 to 100 , and annealed at $600^{\circ} \mathrm{C}$. The electrical, optical, morphological, and structural properties were analyzed as a function of oxygen mixing percentage (OMP). The crystallinity of the cubic structured ZTO thin-film is found to be high at 25 OMP, and it is gradually decreased with increased OMP. The surface morphology of the thin-film is observed, and roughness is measured from the atomic force microscope. Raman Spectroscopy investigated the phase formation and the vibrational modes of the thin-film with their spectral de-convolution. The ZTO thin-films optical properties were investigated using transmittance spectra. The ZTO thin-film indicated the highest refractive index of 2.46, at $633 \mathrm{~nm}$ with optical bandgap values of $3.57 \mathrm{eV}$, with a thickness of $145 \mathrm{~nm}$ and $25 \mathrm{OMP}$. The refractive index, thin-film thickness, and excitation coefficient were analyzed using the Swanepoel envelope technique. Electrical characteristics of ZTO thin-film are measured from the optimized conditions of the thin-film with conventional thermionic emission (TE) technique.
\end{abstract}

Keywords: Thin-film; Optical properties; Swanepoel envelope technique. 


\section{Introduction:}

For several decades, metal oxide semiconductor (MOS) thin-films play a significant role in the interdisciplinary research areas, and it's applications. In the present scenario, researchers are working on MOS composites. Generally, metal oxide composites form ABX3 perovskites. Here ' $\mathrm{X}$ ' is anions such as $\mathrm{O}, \mathrm{F}, \mathrm{I}, \mathrm{N}$, or halogens. 'B' is transition metal elements such as Ti, $\mathrm{Mg}, \mathrm{Pb}, \mathrm{Fe}, \mathrm{Cu}, \mathrm{Ta}, \mathrm{Zr}, \mathrm{Al}, \mathrm{Cr}, \mathrm{Mn}$. 'A' is metal cations such as $\mathrm{Ca}, \mathrm{Zn}, \mathrm{Ag}, \mathrm{Cs}, \mathrm{K}, \mathrm{Na}, \mathrm{Cd}, \mathrm{Pb}, \mathrm{Ba}, \mathrm{La}[1]$. Fuel cells, non-linear optics, memory devices, gas sensors, photocatalysis, solar energy conversion, water splitting, decomposition are some of the essential perovskite applications [2][3][4]. The metal oxides such as $\mathrm{ZnO}, \mathrm{TiO}_{2}, \mathrm{SnO}_{2}, \mathrm{MnO}_{2}$, $\mathrm{CuO}, \mathrm{WO}_{3}$ are known as wideband semiconductors [5]. Among these metal oxides, $\mathrm{ZnO}$ and $\mathrm{TiO}_{2}$ thinfilms have extensive applications of their intrinsic properties, mixed oxides formations, and transition metal doping. Incorporation of $\mathrm{ZnO}$ with $\mathrm{TiO}_{2}$ leads to $\mathrm{Zn}$-Ti-O ternary oxides which ensure the separation of electron-hole pair efficiently [6]. Under the light illumination, it contributes to optoelectronic devices' applications such as photovoltaic and dye-sensitized solar cells, light-emitting diodes, sensors, flat panel displays, and photodetectors. $\mathrm{ZnO}-\mathrm{TiO}_{2}$ composite exists in zinc Orthotitanate $\left(\mathrm{Zn}_{2} \mathrm{TiO}_{4}\right.$, cubic spinel crystal structure), zinc titanate $\left(\mathrm{ZnTiO}_{3}\right.$, either cubic spinel or hexagonal perovskite structure), and zinc poly titanate $\left(\mathrm{Zn}_{2} \mathrm{Ti}_{3} \mathrm{O}_{8}\right.$, cubic spinel structure $)$ [7][8]. The ideal cubic crystal structure of $\mathrm{ZnTiO}_{3}$ is rare and often distorted with reduced symmetry[9].

However, To obtain good quality stoichiometric and crystalline thin-films: dopants, chemical composition, substrate temperatures, annealing temperatures, minimum thickness, required phase, and suitable oxygen atmosphere are very important. A small weight percentage (1 wt. \%) of $\mathrm{SnO}_{2}$ has doped to ZTO stoichiometric composition. It improves the properties of ZTO thin-film because a small quantity of $\mathrm{SnO}_{2}$ can enhance the intensity of the cubic nature of ZTO thin-film and increases the surface adatom mobility of the charges, which leads to the coalition of smaller grains[10][11][12]. Several researchers studied the effect of oxygen mean pressures and concluded the impact of OMP on the thin-films structural, electrical, and optical properties. The phase composition, crystal structure, and optical behavior of the metal oxide thin-films can be controlled by adjusting the oxygen flow rate in the sputtering process [13-16].

In this paper, a systematic study on structural, optical, morphological, and electrical properties of $\mathrm{ZnTiO}_{3}$ thin-films deposited at oxygen mean pressures (OMP) variant by Radio Frequency sputtering is 
reported. A small concentration of $\mathrm{SnO}_{2}$ was doped to the ZTO sputtering target. The crystallinity and structure are determined with XRD. The thin-film optical constants, thickness, and excitation coefficients of ZTO thin-films were measured using the Swanepoel envelope technique. Roughness and morphology were observed from AFM, The best and optimized conditions were used to determine I - V characteristics of ZTO thin-film deposited on N-Si substrate with Ag electrodes. As per the author's knowledge, there are very few literatures available for I - V characteristics of ZTO thin-film.

\section{Experimental Procedure:}

The $\mathrm{ZnTiO}_{3}$ (ZTO) thin-films were deposited on quartz and N-Si substrates using the RF magnetron sputtering method. The stoichiometric $\mathrm{ZnTiO}_{3}(\mathrm{ZTO})$ with a small weight percentage (1 wt. \%) of $\mathrm{SnO}_{2}$ produced a sputtering target using the conventional solid-state reaction method. Zinc Oxide (ZnO, 30nm, 99.8\% pure, SSA $\sim 35 \mathrm{~m}^{2} / \mathrm{g}$, Zincite phase), Titanium Dioxide $\left(\mathrm{TiO}_{2}, \sim 35 \mathrm{~nm}, 99.9 \%\right.$ pure, SSA $\sim 60 \pm 20 \mathrm{~m}^{2} / \mathrm{g}$, Anatase phase), Tin Oxide $\left(\mathrm{SnO}_{2}, \sim 80 \mathrm{~nm}, 99.9 \%\right.$ pure, $\mathrm{SSA} \sim 11 \mathrm{~m}^{2} / \mathrm{g}$, cassiterite phase) elementary powders were mixed using a planetary ball mill (Fritsch GmbH, Germany) with prescribed stoichiometry. The mixed powders were dried to room temperature. The powders were uni-axially pressed to produces a $\mathrm{ZnTiO}_{3}$ target of $60 \mathrm{~mm}$ diameter and sintered at $450 \square \mathrm{C}$ for 4 hours. Before deposition, the sputter chamber has been evacuated up to $1.0 \times 10^{-6} \mathrm{~m} \mathrm{bar}$ base pressure. To obtain $3.0 \times 10^{-2} \mathrm{~m}$ bar pressure, the chamber is pumped with argon $(\mathrm{Ar})$ and oxygen $(\mathrm{O})$ gases. The sputtering power is fixed to 50W. The ZTO thin-films were deposited at room temperature and annealed at $600^{\circ} \mathrm{C}$. For the uniform deposition rate, and the same thickness, different levels of oxygen (O) and Argon (Ar) gases were applied to the chamber. The thickness of the films and deposition rate were optimized using UV-VIS Spectroscopy (Veeco-Dektak 6M). The purity of phase and crystal structure of the thin-films were obtained using an X-ray diffractometer (Rigaku, TTRAX III $18 \mathrm{~kW})$ with $\mathrm{Cu}-\mathrm{K}_{\alpha}$ radiation $(\lambda=1.5406 \AA$ A). Atomic force microscope (Agilent, 5500 series) is employed for the thin-films roughness and surface morphology analysis. ZTO (N-Si, Quartz) thin-film was fabricated, and a top electrode (Ag) was deposited by thermal evaporation. UV-VIS-NIR Spectrophotometer (UV 3101PC, SHIMADZU) is employed for the spectral transmission characteristics in the $200-2500 \mathrm{~nm}$ wavelength range. To study the vibrational modes and FWHM of the thinfilm reviewed from Raman spectroscopy (LABRAM HR800, JOBIN YVON). I-V characteristics of the thin-film were obtained from a 4-point probe station and Keithley (4200 SCS). Table I represents the sputtering conditions of the ZTO thin-film. 


\section{Results \& Discussions:}

\subsection{XRD:}

Fig. 1(a) shows the X-ray diffraction (XRD) patterns of the $\mathrm{ZnTiO}_{3}(\mathrm{ZTO})$ thin-films grown at room temperature under various oxygen atmosphere conditions (0-100\%). It is seen that the thin-film deposited at room temperature is purely amorphous, which is indicating that no crystallization occurred. At $600^{\circ} \mathrm{C}$, the $\mathrm{ZnTiO}_{3}$ phase was found, and all peaks are confined to a cubic perovskite structure(ICDD:00-039-0190). No secondary phases were found in the composite[17][18].

Main reflections are obtained at (2 20 ), (3 3 1), (4 2 2 2), (5 11 1), (4 $\left.4 \begin{array}{ll}4\end{array}\right)$ planes. The plane (3 111$)$ at $2 \theta=35.58^{\circ}$ is the predominant peak. The highest intensity of peak at $2 \theta=51.75^{\circ}$ is Si substrate. Which indicates the orientation of $\mathrm{ZnTiO}_{3}$ thin-film grown on $\mathrm{N}$-type $\mathrm{Si}$ substrate. Crystallite size $(P)$ is calculated from Scherrer approximation, which is defined as

$$
P=\frac{0.9 \lambda}{\beta_{h k l} \operatorname{Cos} \theta}
$$

Where $P$ is the crystallite size in $\mathrm{nm}, \beta_{h k l}$ is a full-width half-maximum of the peak in radians, $\lambda$ is the wavelength of radiation (1.54056 $\dot{\mathrm{A}}$ for $\mathrm{Cuk} \alpha)$, and $\theta$ is Bragg angle.

The average crystallite size calculated with the equation (1) was increased from $3.5 \mathrm{~nm}$ to $6.19 \mathrm{~nm}$, with an increase of OMP from 0 to 25 . Crystallite size decreases from 6.19 to $4.2 \mathrm{~nm}$ with an increase of OMP from 25 to 100 , which is confined to the nanocrystalline nature of $\mathrm{ZnTiO}_{3}$. It can be correlated that, the sputtered atoms react with oxygen molecules which generates redistribution of energy and heat on the substrate's surface. This process concurrently promotes sputtered species migration and crystallization. For ZTO thin-films initially, $\mathrm{O}_{2}$ helps the crystalline growth up to $25 \mathrm{OMP}$, then the growth gradually decayed up to $100 \mathrm{OMP}$. The trends in lattice volume, D spacing, crystallite size, lattice strain, and lattice constant with respect to OMP were calculated and represented in Fig.1(b). The thin film deposited at $12.5 \%$ OMP to $25 \%$ OMP is the better condition for ZnTiO3 thin film fabrication. 


\subsection{AFM:}

Fig. 2 shows the surface morphology, holographic roughness(internal), and typical 3-D representation of ZTO thin-films deposited with different OMP's. The images are obtained from Atomic force microscopy. The average roughness to be an increase from $0.25 \mathrm{~nm}$ to $0.74 \mathrm{~nm}$ with the increase of OMP from 0 to 25 and roughness decreases from $0.74 \mathrm{~nm}$ to $0.48 \mathrm{~nm}$ with the rise of OMP from 25 to 100 . AFM micrographs follow the same trend observed from XRD. But the films deposited in 100\% oxygen and 0\% oxygen atmosphere exhibited a uniform and homogeneous but low dense microstructure with regards to surface topology and thickness. The grain growth enhancement may be optimized at 25 OMP for ZTO thin-film to improve the films' crystallization in oxygen and argon mixed atmosphere. The roughness value is $<1 \mathrm{~nm}$ is depicted in ultra-fine thin-films deposited by the sputtering technique. The small roughness peaks can act as nanostructured absorption sites for sensing applications [19][20]. Fig.3 represents the RMS roughness of the deposited thinfilms.

\subsection{Optical properties (UV-Visible Spectroscopy) :}

Fig. 4(a) depicts the transmittance spectra of ZTO thin-films fabricated on the quartz substrates. It is computed on a scale of 200-2500 nm wavelength. In the visible range, thin-films were transparent (>75\%), and Fabry- Pérot interference behavior was perceived. Because of the thin-films fundamental absorption, the transmittance was decreased to zero in the wavelength range of 235-265 nm. The absorption edges show a bathochromic shift with increasing the OMP. The optical constants were determined by using the Swanepoel envelope technique [21][22]. The refractive index computed from the following equation,

$$
n=\mathbf{W}+\mathbf{N}^{2}-n_{S}^{2} \boldsymbol{-}^{\mathrm{N} / \mathrm{T} / 2}
$$

Where,

$$
N=2 n_{s}^{2}\left(\frac{T_{\max }-T_{\min }}{T_{\max } * T_{\min }}\right)+\frac{n_{s}^{2}+1}{2}
$$

$T_{\max }$ is the transmittance maxima and $T_{\min }$ is the transmittance minima at a specific wavelength $\lambda$, and $n_{s}$ is the substrate's refractive index. The thin-films thickness $(d)$ can be calculated by the following equation,

$$
d=\frac{\lambda_{1} * \lambda_{2}}{2 \boldsymbol{Q}_{1} * n_{2}-\lambda_{2} * n_{1}}
$$

$n_{1}$ and $n_{2}$ are the refractive indices of two adjacent maxima or minima at wavelengths $\lambda_{1}$ and $\lambda_{2}$. 
The films' thicknesses were in the range of $160-177 \mathrm{~nm}$ is almost constant. It is calculated that the refractive index $(n)$ of the thin-films was from 2.35 to 2.46. It follows the same trend as XRD and AFM. usually, the refractive index depends on the thin-films crystallinity, electronic structure, and oxygen deficiencies.

The optical band gap energy $\left(E_{\mathrm{g}}\right)$ of the thin-films are acquired from the extrapolated linear portion of $(\alpha h v)^{\mathrm{m}}$ vs $(h v)$ curve, where $h v$ is the photon energy, $\alpha$ is the absorption coefficient. The measure of crystalline order $\beta$ related to the bandgap energy is $(\alpha h v)^{\mathrm{m}}=\beta\left(h v-E_{g}\right)$. The bandgap energy $\left(E_{g}\right)$ is calculated by considering an allowed direct $(\mathrm{m}=2)$ transition of electron between the highest occupied state of the valence band and the lowest unoccupied state of the conduction band. The thin-films absorption edges at different OMP were shown in Fig. 4(b). It is observed that the optical bandgap energy values are in the range of $3.39-3.60 \mathrm{eV}$. The bandgap variations might be due to reduced oxygen vacancies, variations in crystallinity, and improved grain size [23]. Fig. 4(c) represents the refractive index $\left(n_{f}\right)$, absorption coefficient $(\alpha)$, Excitation coefficient $(\mathrm{K})$, and optical energy bandgap $\left(E_{g}\right)$ of the ZTO films concerning different OMP's.

\subsection{EDS:}

The Energy dispersive spectrum technique confirmed the elemental distribution of the ZTO composite. Fig 5(a) shows the typical microstructure, elemental mapping, and Fig 5 (b) depicts the energy-dispersive spectra of ZTO composite deposited on the $\mathrm{N}$-si substrate at $25 \mathrm{OMP}$ condition. The experimental volume fraction of ZTO composition is in agreement with theoretical volume fractions, confirming the ZTO composite's stoichiometry. The peaks in the spectrum are similar to X-ray diffraction peaks. The predominant peak in the spectrum is $\mathrm{N}-\mathrm{Si}$ substrate, which represents the orientation of the thin-film on $\left(\begin{array}{lll}1 & 0 & 0\end{array}\right) \mathrm{N}$ - Si substrate.

\subsection{Raman Spectra:}

Fig. 6 exhibits the Raman spectra of ZTO composite recorded in the wavenumber range from 50 to 1000 $\mathrm{cm}^{-1}$ and their spectral de-convolution, the spectrum was fitted with Gaussian function using origin pro software. Seven to eight active Raman modes were identified for deposited ZTO thin-film at different OMP. Table II represents the Raman modes and full width at half maxima. The bands persist cubic phase of ZTO, displays two large and broad bands at $310.464 \mathrm{~cm}^{-1}, 432.600 \mathrm{~cm}^{-1}$, and all the spectral features are of the first order. The result can be explained based on the order-disorder model of the central Ti ion. According to group theory $\mathrm{ZnTiO}_{3} \mathrm{has}$ ten Raman active modes $5 \mathrm{~A}_{\mathrm{g}}+5 \mathrm{E}_{\mathrm{g}}$. The bands at $102 \mathrm{~cm}^{-1}, 153 \mathrm{~cm}^{-1}, 433 \mathrm{~cm}^{-1}, 583 \mathrm{~cm}^{-1}$ are the $\mathrm{E}_{\mathrm{g}}$ modes and $310 \mathrm{~cm}^{-1}, 489 \mathrm{~cm}^{-1}, 795 \mathrm{~cm}^{-1}$ are related to Ag modes of the ZTO Raman spectra [24][25]. 


\subsection{I-V Characteristics:}

Fig. 7 shows the I - V characteristics of $\mathrm{ZnTiO}_{3}$ thin-film on N-type Silicon substrate which deposited at 25 oxygen mixing percentage. The Ag electrodes were deposited on a thin-film with thermal evaporation sputtering unit. From the characteristics, it was observed that the thin-film was having a non-linear and symmetrical response for both forward and reverse bias. The high resistivity of the film is observed. In general, chemically deposited films have high resistance. It is due to low donor defect density and a large number of chemisorbed oxygen species. A large number of oxygen molecules are chemisorbed at the grain boundaries and on the thin-films surface. The surface resistance of the thin-film measured from the four-probe station is $\mathrm{R}_{\mathrm{S}}=5.59 * 10^{9} \Omega$

Chemisorption is the process of trapping conduction electrons from the negatively charged oxygen species $\left(\mathrm{O}^{2-}, \mathrm{O}^{-}\right)$. Due to this chemisorbed species, the resistivity of the oxide surface is high. For reducing gas molecules, the negatively charged chemisorbed species act as reaction centers. When reduction gases come in contact with the oxide surface, the trapped electrons releases because of the reaction between gas molecules and the oxygen species. The electrons return to the conduction band so the resistance is decreased. After the removal of the gas, the electrons are again trapped, and the resistance increases. Thus such high resistive films containing an enhanced density of chemisorbed species are particularly suitable for resistive mode gas sensor applications[26].

From the conventional thermionic emission (TE) theory, the forward I-V characteristics of the ZTO thinfilm deposited on N-type Si substrate with Ag contacts can be delineated by

$$
I=I_{0} \exp \left(\frac{\left(V-I R_{S}\right) q}{\eta k T}\right)
$$

Where $I_{0}$ is the reverse saturation current, $V$ is the applied voltage, $R$ s is the series resistance, $\eta$ is the ideality factor, $\mathrm{q}$ is the charge, $\mathrm{k}$ is the Boltzmann constant, and $\mathrm{T}$ is the absolute temperature.

The reverse saturation current $\mathrm{I}_{\mathrm{o}}$ is given by

$$
I_{0}=A A^{*} T^{2} \exp \left(\frac{-q \phi_{B, e f f}}{k T}\right)
$$

where A is the contact area of ZTO $\left(\sim 0765 \times 10^{-2} \mathrm{~cm}^{-2}\right), \mathrm{A}^{*}$ is the effective Richardson constant of ZTO $\left(\sim 37 \mathrm{~A} \mathrm{~cm}^{-2} \mathrm{~K}^{-2}\right)$, and $\phi_{\mathrm{B}}$, eff is the effective barrier height at zero bias. It is described as 


$$
\phi_{B, e f f}=-\frac{k T}{q} \ln \left(\frac{I_{0}}{A A^{*} T^{2}}\right)
$$

Taking natural logarithm on both sides of Eq. (1), we obtain

$$
\ln (I)=\ln \left(I_{0}\right)+\frac{q\left(V-I R_{S}\right)}{\eta k T}
$$

For a low current region of the forward bias $\mathrm{I}-\mathrm{V}$ characteristics, the forward bias current is in the order of $\mathrm{I}_{0}$, the effect of Rs is negligible due to the negligible value of IRs. Thus, the reverse saturation current value $\mathrm{I}_{0}$ can be calculated from the intercept of $\ln$ I versus V plot (shown in Fig. 8(a)) with the current(I) axis for V $=0$, which gives $\mathrm{I}_{0} \sim 5.833 \times 10^{-11}$ A. The value of $\mathrm{I}_{0}$ is then used in Eq. (7) to determine the value of $\phi_{\mathrm{B}}$, eff as 0.87 $\mathrm{eV}$. This value may be deviated from the ideal value because of high surface states, generation-recombination, image force lowering effect in the depletion region, and the barrier inhomogeneities at the junction. Now, the ideality factor $(\eta)$ is computed from the slope of the linear region of the forward bias $\ln I$ versus $V$ plot as

$$
\eta=\frac{q}{k T}\left(\frac{d V}{d \ln (I)}\right)
$$

From Eq. (9), the ideality factor $(\eta)$ is estimated as $\sim 2.35$, which is much larger than unity. The high $\eta$ values represent the interfacial thin oxide layer, a wide distribution of barrier height, and the bias voltage dependence of the barrier height[27][28].

To determine the value of the device's series resistance, we have used the $\mathrm{Ri}=\mathrm{dV} / \mathrm{dI}$ vs $\mathrm{V}$ plot of the measured I-V data, as shown in Fig. 8(b). where Ri is the bias-dependent resistance. The series resistance is almost negligible at lower values of current. At higher values of current Rs shows a significant effect so that it exhibits nonlinear characteristics. In the high current region, the voltage drop IRs is much larger than the voltage appearing across the ZTO thin-film and hence applied bias V $=$ IRs. The input resistance Ri $\sim 2.3 * 10^{9}$ is determined from Fig. 8(c).

\section{Conclusions:}


RF magnetron sputtering was used to deposit ZTO thin-films on quartz, N-Si substrates. The influences of the OMP on structural, optical, morphological, and electrical properties were studied systematically. The deposited thin-films annealed at $600^{\circ} \mathrm{C}$ were crystallized in pure ZTO cubic phase without any secondary phases. The roughness value is $<1 \mathrm{~nm}$ is depicted in ultra-fine thin-films deposited by the sputtering technique. The thinfilms refractive index is high at $25 \mathrm{OMP}$ is 2.46 , whereas the optical band gap varies from $3.4 \mathrm{eV}$ to $3.6 \mathrm{eV}$ with varying OMP. The stoichiometry of the thin-film meets the elemental composition. The vibrational modes of the Raman spectra representing the cubic structure of ZTO. The electrical parameters of the thin-films are Reverse saturation current $\mathrm{I}_{0}$ is $5.83 \times 10^{-11} \mathrm{~A}$, Barrier efficiency is $\phi_{\mathrm{B}}$, eff is $0.87 \mathrm{eV}$, and ideality factor $\eta$ is 2.35 . The thinfilm parameters are more suitable for optoelectronic, microwave dielectric, and gas sensing applications.

\section{Acknowledgments:}

\section{References:}

[1] R. J. D. Tilley, Perovskites Structure-Property Relationships, 1st ed. johns Wiley, 2016.

[2] V. Chellappan and S. Ramakrishna, "ScienceDirect Perovskites : Solar cells \& engineering applications - materials and device developments," vol. 122, pp. 678-699, 2015.

[3] S. Brittman, G. Widia, P. Adhyaksa, and E. C. Garnett, "The expanding world of hybrid perovskites : materials properties and emerging applications," vol. 5, no. 1, pp. 7-26, 2020.

[4] Q. Chen, N. De Marco, Y. Michael, T. Song, C. Chen, and H. Zhao, "Under the spotlight : The organicinorganic hybrid halide perovskite for optoelectronic applications," Nano Today, 2015.

[5] J. Zhao and X. Cheng, "Eighteen functional monolayer metal oxides: wide bandgap semiconductors with superior oxidation resistance and ultrahigh carrier mobility,” vol. 4, no. 3, 2019.

[6] Miriam Yuste, Ramon Escobar-Galindo, Noelia Benito, Carlos Palacio, Oscar Martínez, Jose Maria Albella and Olga Sánchez., "Effect of the Incorporation of Titanium on the Optical Properties of $\mathrm{ZnO}$ Thin-films : From Doping to Mixed Oxide Formation.”, Coatings vol. 9, no. 180, 2019.

[7] Richard a. Slepetys Stanley f. Bartram, "Compound Formation and Crystal Structure in the System," October, 1961. 
[8] D. Tsai, Z. Chang, B. Kuo, E. Chen, and F. Shieu, "Phase transformation and dielectric properties of sputtering-prepared Zn - Ti - O thin-films,” Ceram. Int., vol. 45, no. 10, pp. 12814-12819, 2019.

[9] M. W. Lufaso and P. M. Woodward, "research papers Prediction of the crystal structures of perovskites using the software program SPuDS research papers,” pp. 725-738, 2001.

[10] V. Kumar, P. Kumar, M. Kumar, P. Jain, D. Bhandari, and Y. K. Vijay, "Study of post-annealing influence on structural, chemical and electrical properties of ZTO thin-films," J. Alloys Compd., vol. 509, no. 8, pp. 3541-3546, 2011.

[11] Y. Huang, Y. Lee, D. Tsai, and F. Shieu, "Effect of annealing on formation and microstructure of ZnTiO 3 thin-films by DC reactive magnetron co-sputtering," vol. 687, pp. 610-616, 2011.

[12] Fengwan Guo, Xiangyu Sun, Bing Liu, Zijiang Yang, Jing Wei, Dongsheng Xu, "Enhanced Lifetime and Photostability with Low-Temperature Mesoporous ZnTiO 3 / Compact SnO 2 Electrodes in Perovskite Solar Cells,” pp. 1-7, 2019.

[13] N. Aghilizadeh, A. H. Sari, D. Dorranian, "Role of Ar / O 2 mixture on structural, compositional and optical properties of thin copper oxide films deposited by DC magnetron sputtering," J. Theor. Appl. Phys., vol. 11, no. 4, pp. 285-290, 2017.

[14] B. Abdallah, A. K. Jazmati, R. Refaai, and A. E. Commission, "Oxygen Effect on Structural and Optical Properties of ZnO Thin-films Deposited by RF Magnetron Sputtering,” vol. 20, no. 3, pp. 607-612, 2017.

[15] N. Madaoui, L. Bait, K. Kheyar, and N. Saoula, "Effect of Argon-Oxygen Mixing Gas during Magnetron Sputtering on TiO2 Coatings,”vol. 2017, 2017.

[16] P. Gogoi, P. Srinivas, P. Sharma, and D. Pamu, “Optical, Dielectric Characterization and Impedance Spectroscopy of Ni-Substituted MgTiO3 Thin-films,” 2015.

[17] C. Ye, Y. Wang, Y. Ye, J. Zhang, and G. H. Li, "Preparation and photoluminescence of undoped ZnTiO3 thin-films,”vol. 033520, no. 2009, pp. 1-5, 2012.

[18] Z. L. Shenhui Lei, Huiqing Fan, Xiaohu Ren, Jiawen Fang, Longtao, Ma, "Novel sintering and bandgap engineering of ZnTiO3 ceramics with excellent microwave dielectric properties," vol. 3, no. 311, 2017. 
[19] L. G. Teoh, W. Lu, T. H. Lin, and Y. Lee, “The Effect of Mg Dopant and Oxygen Partial Pressure on Microstructure and Phase Transformation of ZnTiO 3 Thin-films,” vol. 2012, 2012.

[20] S. Wu, W. Yau, C. Tsai, and C. Chou, "Nanotribological behavior of thermal treatment of zinc titanate thin films," no. February 2012.

[21] G. M. Gavrilov, D. A. Minkov, E. Marquez, and S. M. F. Ruano, “Advanced Computer Drawing Envelopes of Transmittance Spectra of Thin-film Specimens,” vol. 3, no. 9, pp. 163-168, 2016.

[22] H. Search, C. Journals, A. Contact, M. Iopscience, and I. P. Address, "Determination of the thickness and optical constants of amorphous silicon," vol. 1214.

[23] · E. G.-R. · M. M.-C. and O. Zelaya-Angel, "Bandgap coupling in photocatalytic activity in $\mathrm{ZnO}-\mathrm{TiO} 2$ thin,” pp. 291-297, 2012.

[24] T. Bernert, L. Bayarjargal, and B. Winkler, "Synthesis and high ( pressure, temperature ) stability of ZnTiO3 polymorphs studied by Raman spectroscopy,” Solid State Sci., vol. 43, pp. 53-58, 2015.

[25] A. L. Cabrera, "Raman Study of Phase Transitions in KNbO3 Raman study of phase transitions in KNbO3," December 2019, 2005

[26] M. Erkovan, E. F, Y. F, and M. Okutan, "I-V Characteristics of Pt x Co $1-\mathrm{x}(\mathrm{x}=0.2,0.5$, and 0.7 ) Thin-films," vol. 2013, 2013.

[27] D. Somvanshi and S. Jit, “Analysis of I - V Characteristics of Pd / ZnO Thin-film / n -Si Schottky Diodes with Series Resistance,” vol. 9, no. 1, pp. 1-6, 2014.

[28] D. K. SCHRODER, SEMICONDUCTOR MATERIAL, AND DEVICE, 3rd edition. A JOHN WILEY \& SONS, INC 
Figures
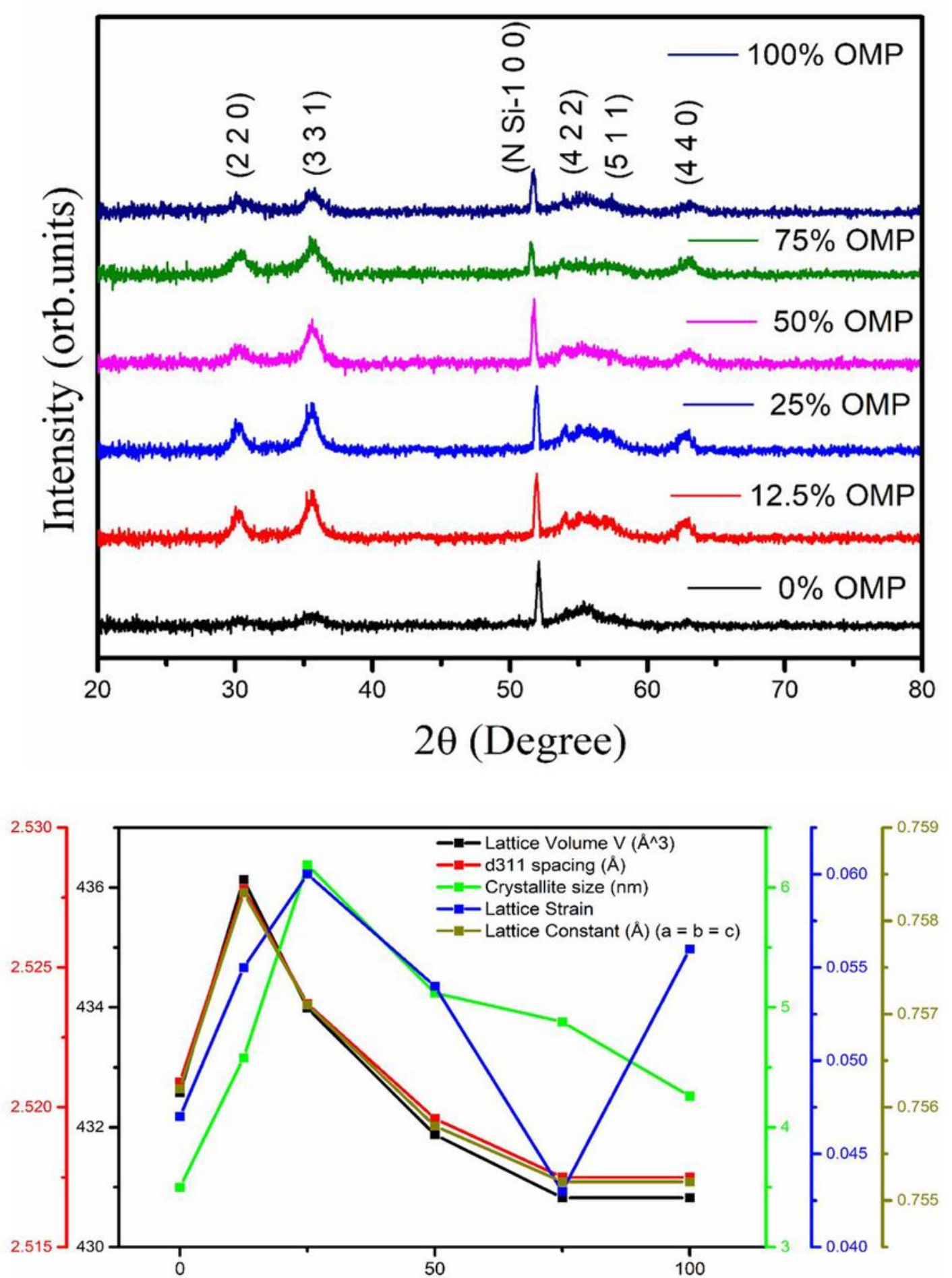

Oxygen Mixing Percentage

Figure 1

(a). XRD patterns of ZnTiO3 thin-film at different Oxygen Mean Pressure (OMP) (Ar = $100 \%$ to $0 \%, 02=0$ $\%$ to $100 \%$ ). (b). Lattice volume, d spacing, Crystallite size, lattice strain of the ZnTiO3 thin-film with respective to Oxygen Mixing Percentage (OMP) ( $\mathrm{Ar}=100 \%$ to $0 \%, 02=0 \%$ to $100 \%$ ). 

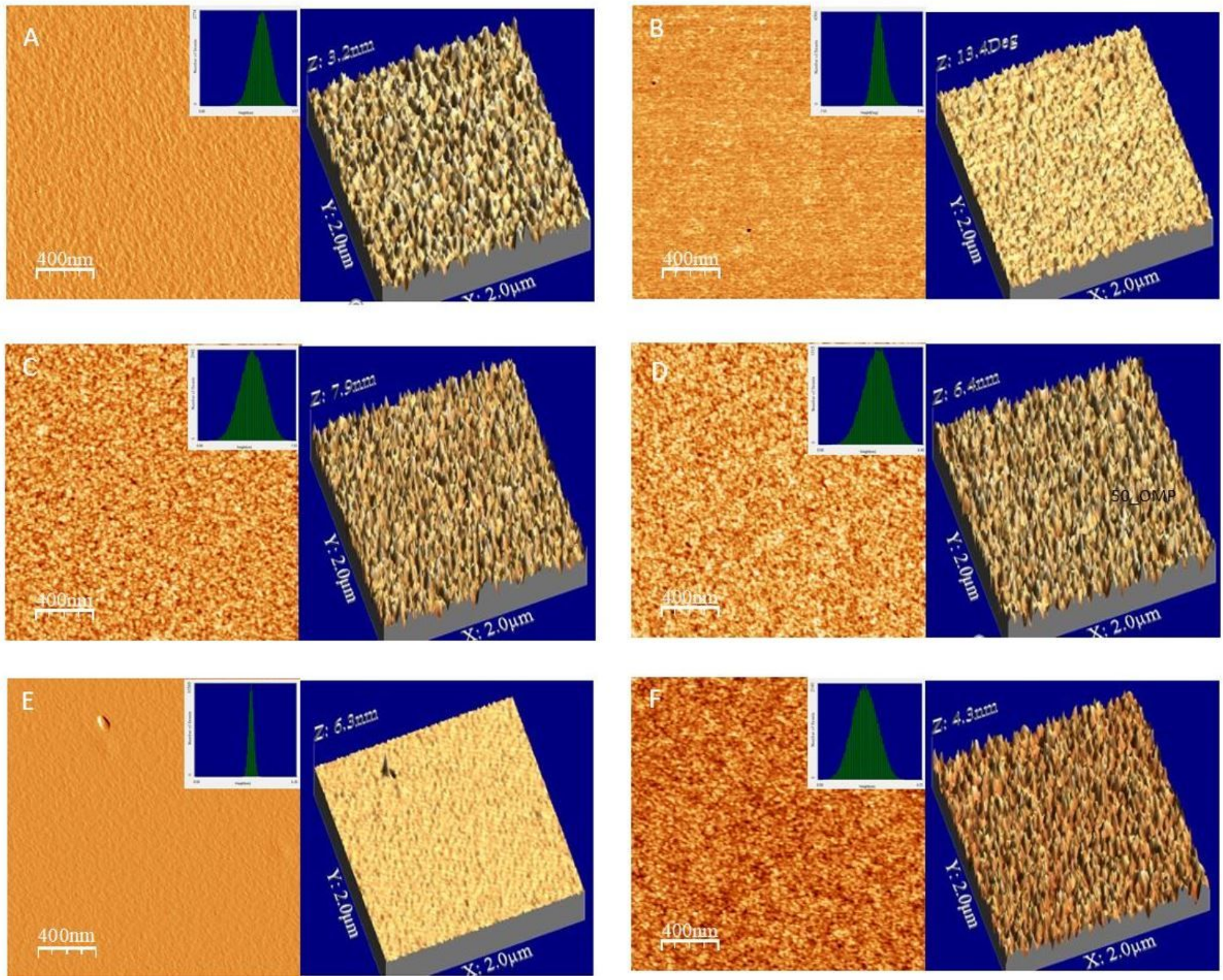

Figure 2

The AFM surface micrographs of the ZnTiO3 thin-films deposited at (a) $0 \%$ ( $\mathrm{Ar}=100 \%, 02=0 \%$ ), (b) $12.5 \%(\mathrm{Ar}=87.5 \%, 02=12.5 \%),(\mathrm{c}) 25 \%(\mathrm{Ar}=75 \%, 02=25 \%),(\mathrm{d}) 50 \%(\mathrm{Ar}=50 \%, 02=50 \%),(\mathrm{e})$ $75 \%(\mathrm{Ar}=25 \%, 02=75 \%)$, (f) $100 \%(\mathrm{Ar}=0 \%, 02=100 \%)$ Oxygen mixing percentages. 


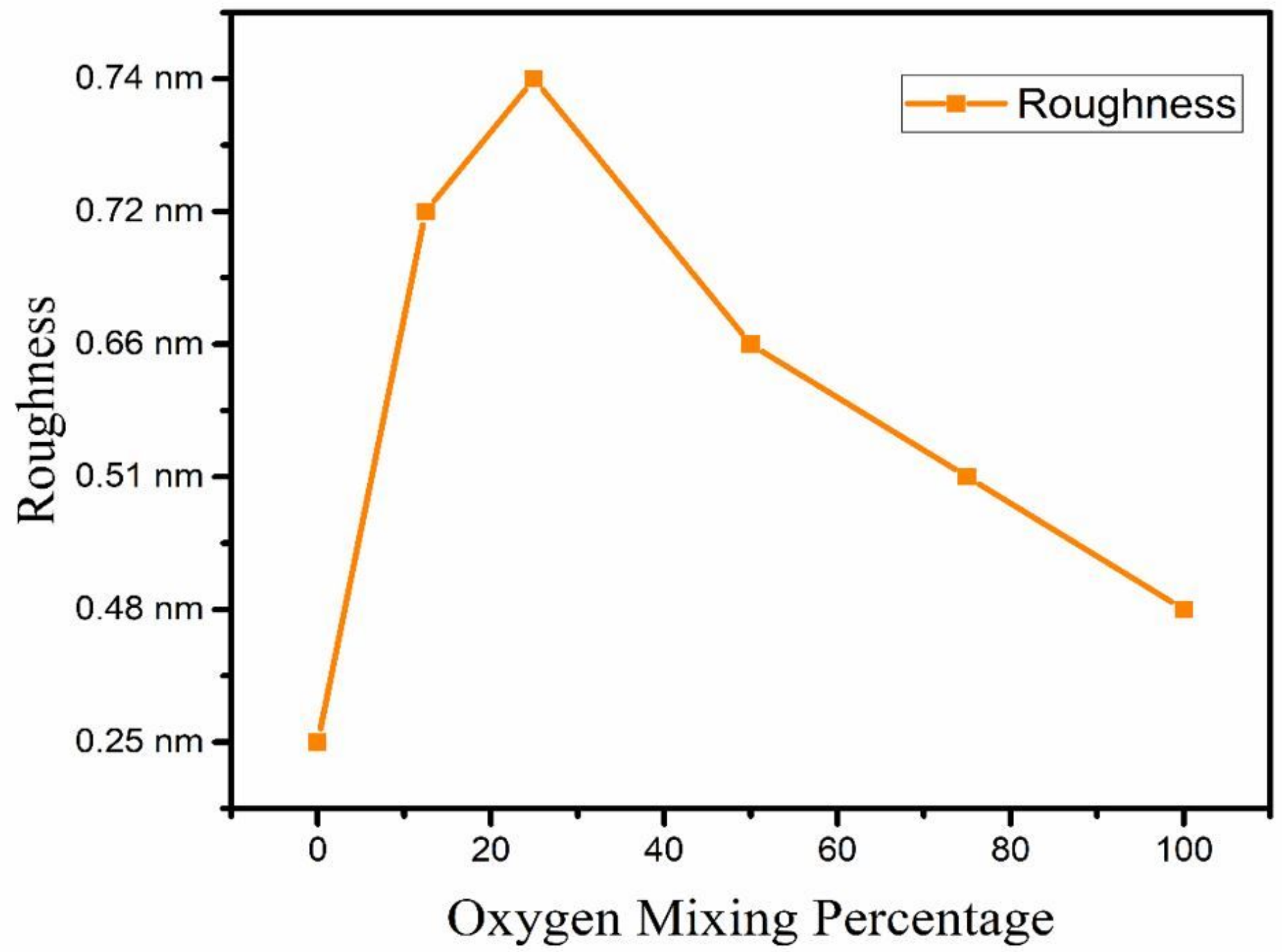

Figure 3

Roughness of the ZnTiO3 thin-film with respective to Oxygen Mixing Percentage (OMP) ( $\mathrm{Ar}=100 \%$ to 0 $\%, 02=0 \%$ to $100 \%)$. 

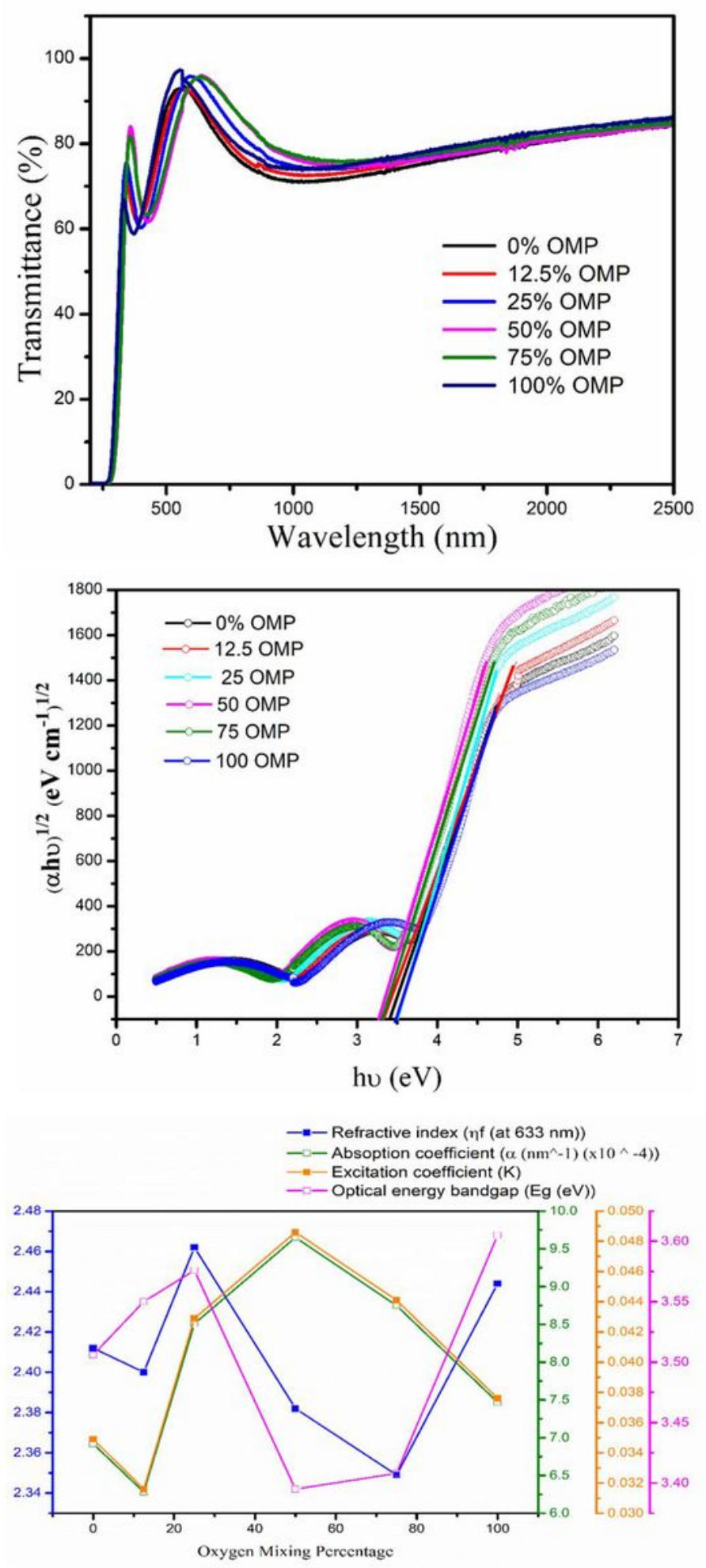

\section{Figure 4}

(a). Transmittance spectra of ZTO thin-films deposited at (Ar $=100 \%$ to $0 \%, 02=0 \%$ to $100 \%$ ) Oxygen mixing percentages. (b). Tauc's plot of ZnTiO3 thin-films deposited at thin-films deposited at ( $\mathrm{Ar}=100 \%$ to $0 \%, 02=0 \%$ to $100 \%$ ) Oxygen mixing percentages. (c). Refractive index (nf), absorption coefficient (a), Extinction coefficient $(\mathrm{K})$ and optical energy bandgap(Eg) of ZnTiO3 thin-film with respect to the Oxygen mixing percentages. 


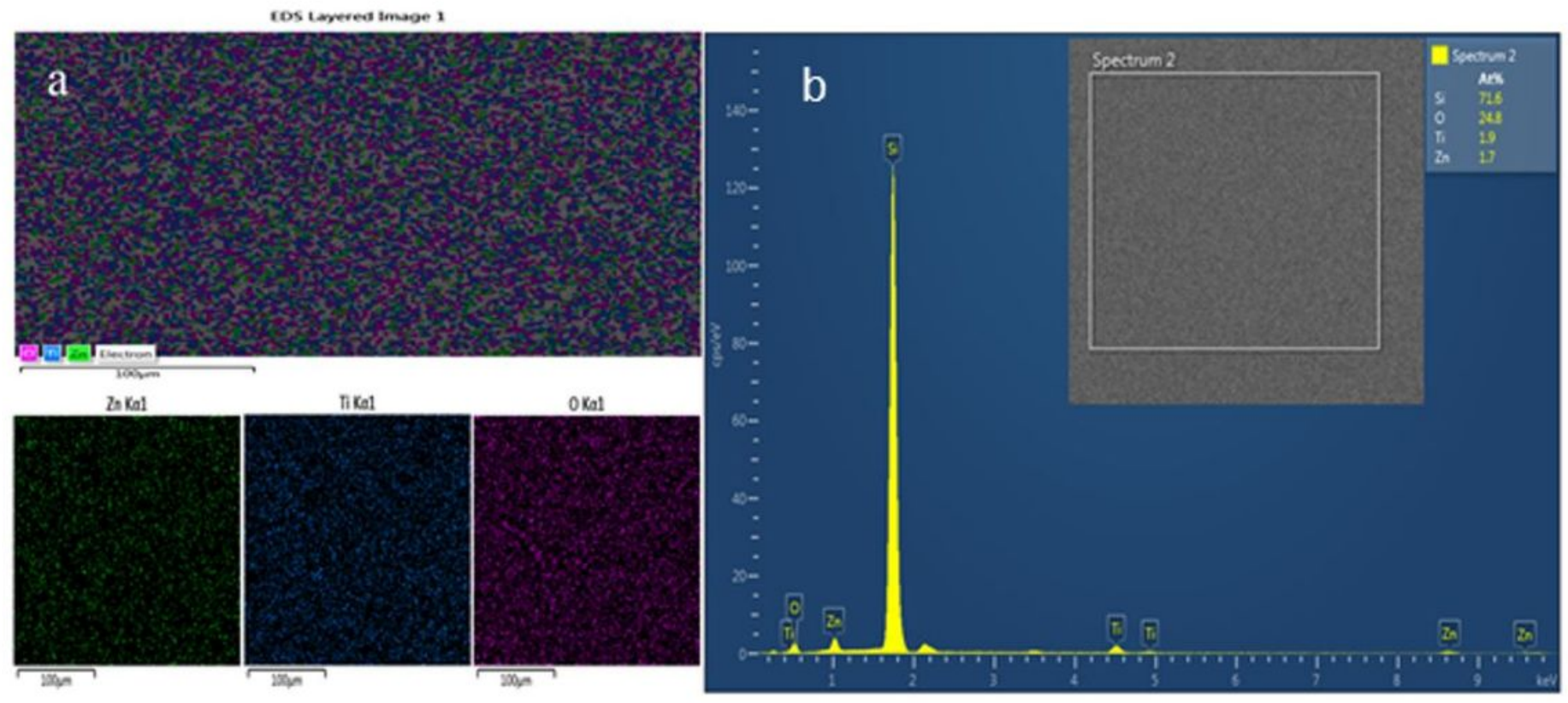

\section{Figure 5}

EDS Spectra of ZnTiO3 thin-film on N-type Si substrate a) the typical microstructure and elemental mapping for 25 Oxygen mixing percentage, b) the EDS Spectra of ZnTiO3 thin-film for 25 OMP. 

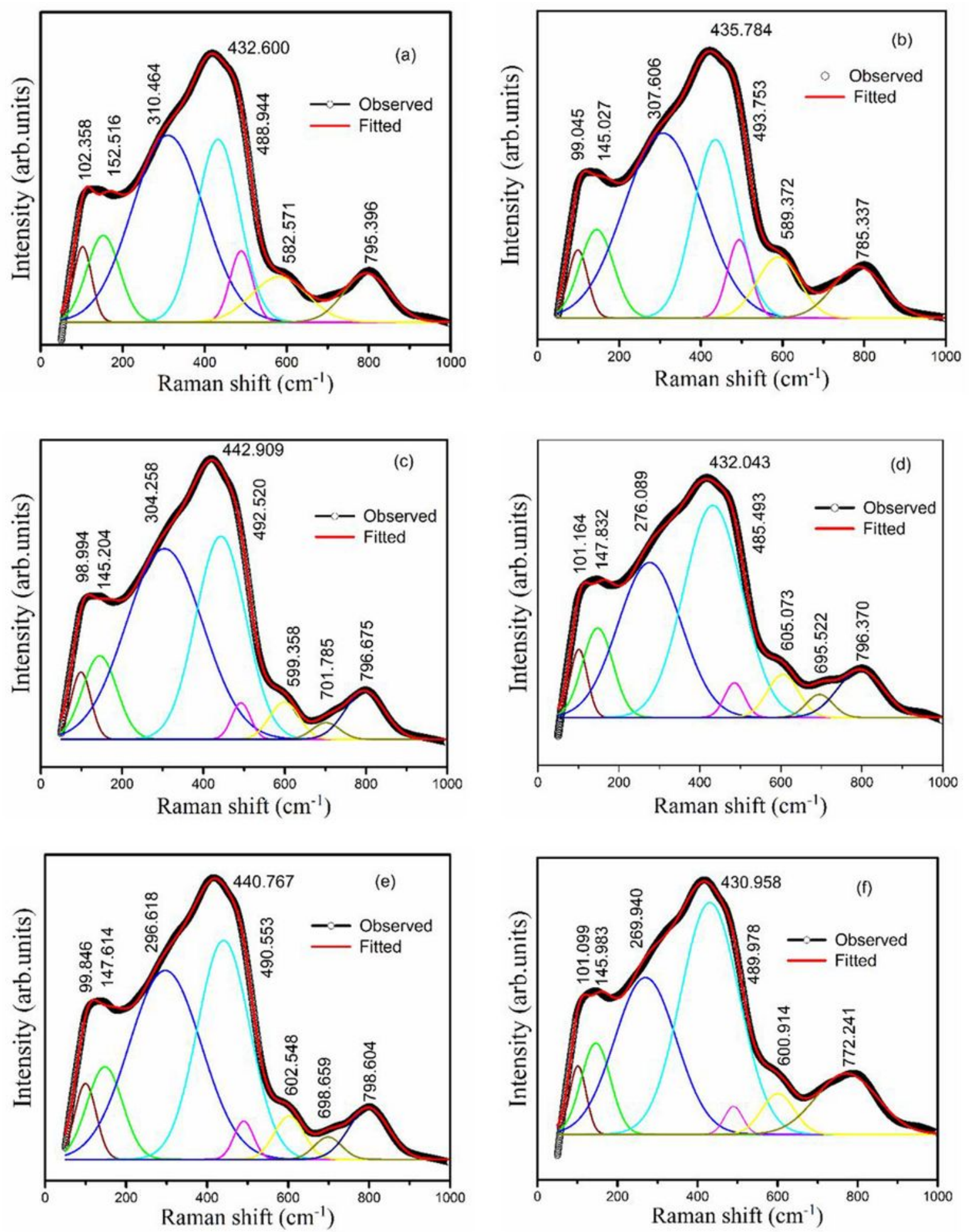

\section{Figure 6}

The Raman spectra of the ZnTiO3 thin-films deposited at (a) 0 OMP, (b) 12.5 OMP, (c) 25 OMP, (d) 50 OMP, e) 75 OMP, (f) 100 OMPs. 


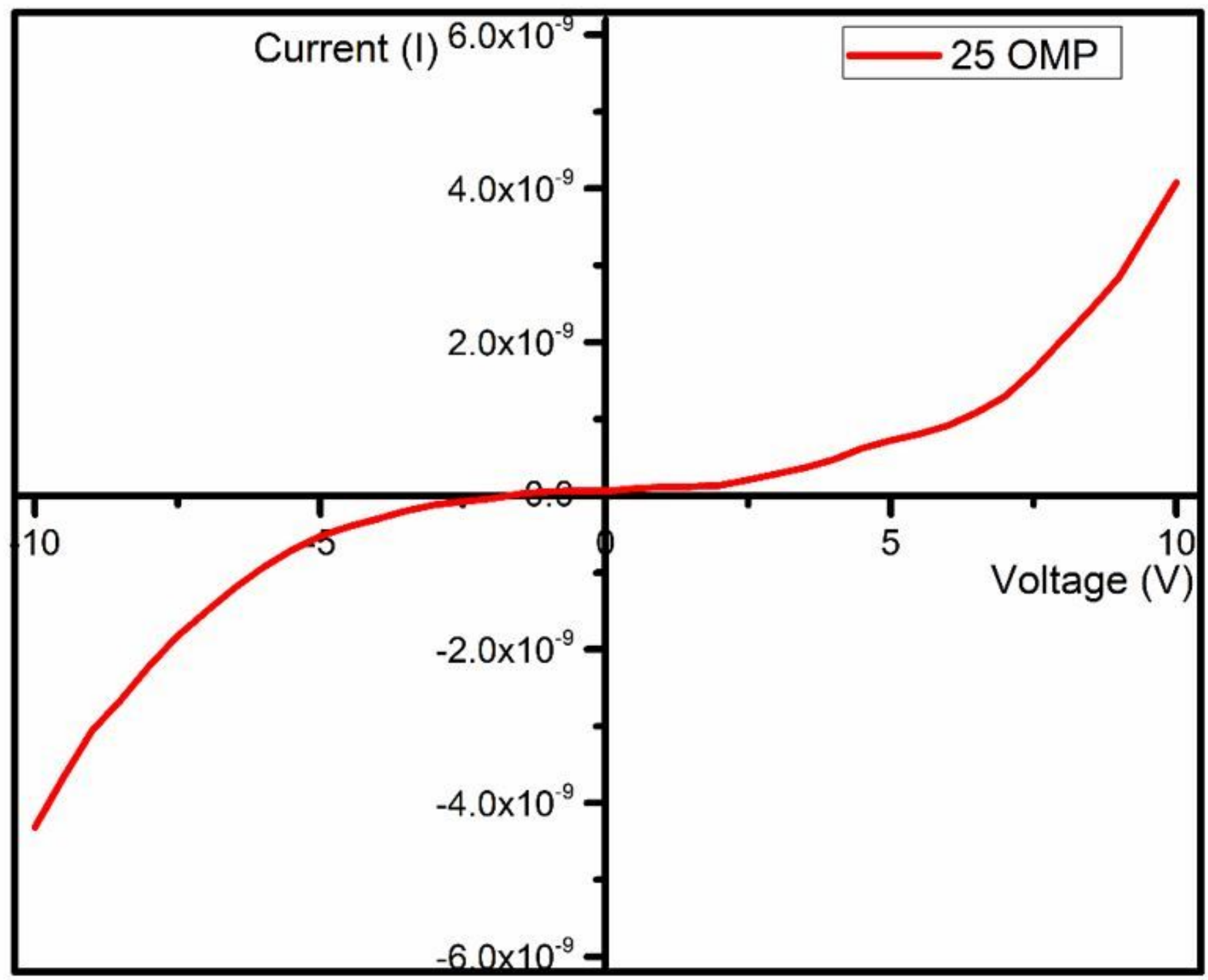

Figure 7

I-V Characteristics of ZnTiO3 thin-film on N-Si substate deposited at 25 OMP. 

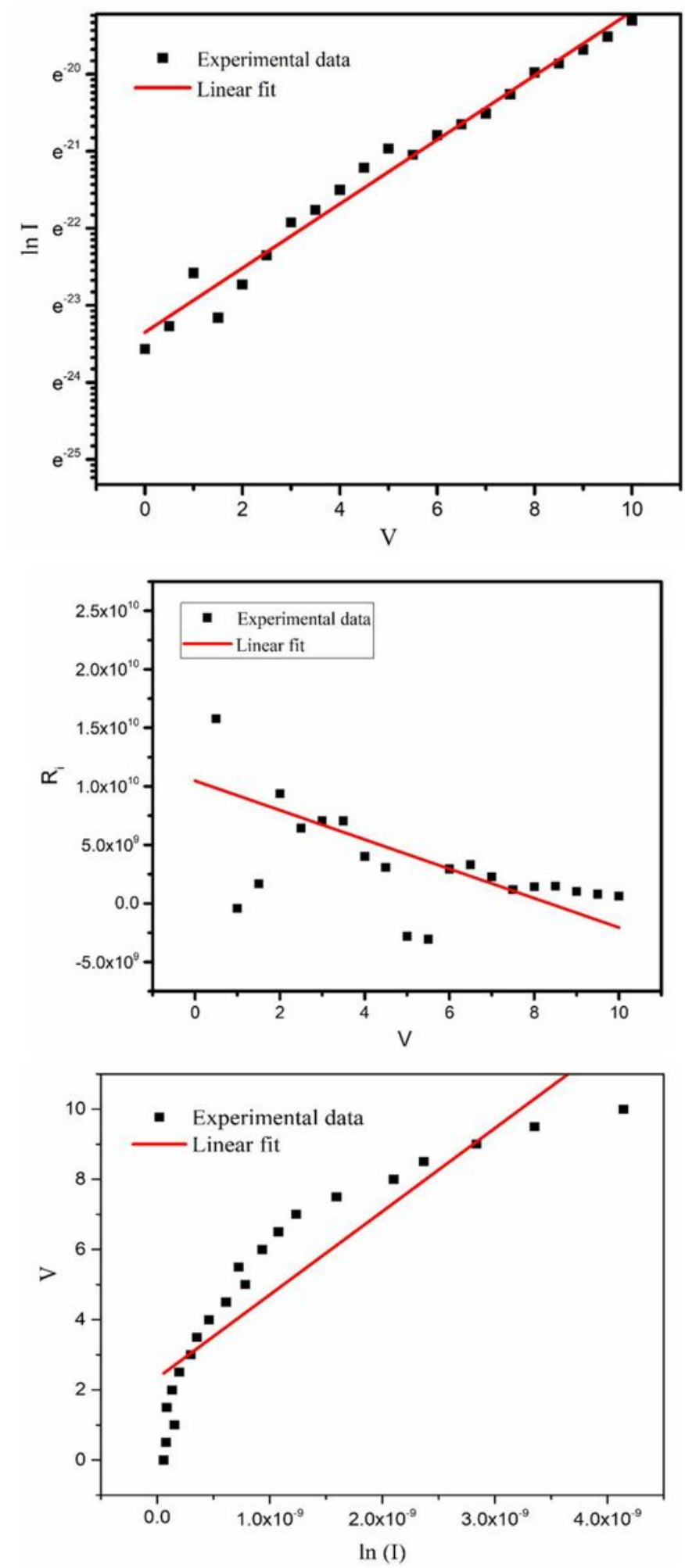

\section{Figure 8}

(a). In (I) - V Characteristics of ZnTiO3 thin-film on N-Si substate deposited at 25 OMP. (b). The biasdependent resistance $\mathrm{Ri}=\mathrm{dV} / \mathrm{dl}$ vs $\mathrm{V}$ Characteristics of ZnTiO3 thin-film on N-Si substate deposited at 25 OMP. (c). V - In (I) Characteristics of ZTO thin-film on N-Si substate deposited at 25 OMP. 